\title{
Global recognition of the importance of nature-based solutions to climate change impacts
}

\author{
Nathalie Seddon ${ }^{\star}$, Elizabeth Daniels ${ }^{2}$, Rowan Davis ${ }^{3}$, Alexandre Chausson ${ }^{1}$, Rian \\ Harris $^{4}$, Xiaoting Hou-Jones ${ }^{5}$, Saleem Huq ${ }^{6}$, Valerie Kapos ${ }^{7}$, Georgina M. Mace ${ }^{8}$, Ali \\ Raza Rizvi ${ }^{9}$, Hannah Reid ${ }^{5}$, Dilys Roe ${ }^{5}$, Beth Turner ${ }^{1}$, and Sylvia Wicander ${ }^{7}$
}

${ }^{1}$ Nature-based Solutions Initiative, Department of Zoology, University of Oxford, Oxford OX1 3PS, UK; ${ }^{2}$ Stockholm Environment Institute, 29 Grove Street, Oxford OX2 7JT, UK; ${ }^{3}$ School of Geography and the Environment, University of Oxford, South Parks Rd, Oxford OX1 3QY, UK; ${ }^{4}$ Faculty of Health Sciences, University of Bristol, Senate House, Tyndall Avenue, Bristol, BS8 1TH, UK; 5 International Institute for Environment and Development, Grays Inn Road, London WC1X 8NH, UK; 6 International Centre for Climate Change and Development, House-27, Road 1, Block-A, Bashundhara R/A, Dhaka 1229, Bangladesh; ${ }^{7}$ UN Environment World Conservation Monitoring Centre, 2019 Huntingdon Road, Cambridge CB3 ODL, UK; ${ }^{8}$ Centre for Biodiversity and Environment Research, University College London, London, UK; 9International Union for the Conservation of Nature, 1630 Connecticut Ave NW, Washington, DC 20009, USA

\section{Non-technical abstract}

Ecosystems across the globe are vulnerable to the effects of climate change, as are the communities that depend on them. However, ecosystems can also protect us from climate change impacts. As the evidence base strengthens, nature-based solutions $(\mathrm{NbS})$ are increasingly prominent in climate change policy, especially in developing nations. Yet intentions rarely translate into measurable targets informed by science. As Paris Agreement signatories revise their Nationally Determined Contributions in time for 2020, we argue that $\mathrm{NbS}$ are key to meeting global goals for climate change and sustainable development and we urge scientists to work with policymakers to identify targets that benefit both people and ecosystems.

\section{Technical abstract}

Ecosystems are not merely vulnerable to climate change but, if sustainably restored and protected, are a major source of human resilience. Not only is the evidence-base for the importance of these "Nature-based Solutions" (NbS) growing rapidly, but $\mathrm{NbS}$ are featuring with increasing prominence in global climate change policy. Here we report on the prominence of $\mathrm{NbS}$ in the 141 adaptation components of the 167 Nationally Determined Contributions (NDCs) that were submitted to UNFCCC by all signatories of the Paris Agreement. In total, 103 nations include $\mathrm{NbS}$ in the adaptation component of their NDC, 76 nations include them in both their adaptation and mitigation component, and an additional 27 include them as part of their mitigation plans only. In other words, 130 nations - or $66 \%$ of all signatories to the Paris Agreement-have articulated intentions of working with ecosystems, in one form or another, to address the causes and consequences of climate change. However, commitments rarely translate into robust science-based targets. As climate pledges are revised in 2020, we urge the ecosystem science community to work closely with policy makers to identify meaningful adaptation targets that benefit both people and the ecosystems on which they depend.

\section{Working with nature for societal good}

Failure to adapt to the effects of climate change has been identified as the single 
greatest risk to health, wealth and wellbeing around the world [1]. Identifying and implementing robust adaptation approaches that are cost-effective and build resilience across a range of potential future climates is therefore critical. To date, the dominant approach has been a mix of direct, engineered (or 'grey') interventions such as sea walls, levees or irrigation infrastructure, and indirect (or 'soft') interventions such as early warning systems and awareness raising [2]. However, there is growing recognition that nature-based (or 'green') solutions ( $\mathrm{NbS}$ ) can provide a powerful complement to these approaches 3 . Indeed, evidence is growing that, when applied strategically and equitably, $\mathrm{NbS}$ not only safeguard biodiversity and store carbon but also help people adapt to the effects of climate change [4-7].

\section{What are 'Nature-based Solutions'?}

$\mathrm{NbS}$ involve working with and enhancing nature to help address societal challenges [810]. They encompass a wide range of actions, such as the protection and management of the natural environment, the incorporation of green and blue infrastructure in urban areas, and application of ecosystem-based principles to agricultural systems. As such, $\mathrm{NbS}$ is an 'umbrella concept' for other established nature-based approaches such as ecosystembased adaptation (EbA) and mitigation (EbM), eco-disaster risk reduction (Eco-DRR), and Green Infrastructure (GI). The concept is grounded in the knowledge that ecosystems produce a diverse range of goods and services on which human wellbeing depends, from storing carbon, controlling floods and stabilizing shorelines and slopes to providing clean air and water, food, fuel, medicines and genetic resources [11]. According to the European Commission, NbS 'bring more, and more diverse, nature and natural features and processes into cities, landscapes and seascapes, through locally adapted, resourceefficient and systemic interventions' [9]. NbS go beyond traditional biodiversity conservation and management by focusing on benefits to both ecosystems and people, enabling sustainable solutions that have the capacity to respond to environmental change over the long-term. They also specifically integrate "societal factors such as human wellbeing and poverty alleviation, socio-economic development, and governance principles." [7]

\section{Nature-based Solutions for climate change mitigation}

Recently, the potential of $\mathrm{NbS}$ to meet global goals for the reduction in greenhouse gas (GHG) emissions (i.e. EbM) has been in the limelight, reflecting the fundamental importance of ecosystems as sources and sinks for CO210. According to one study, the restoration of 350 million hectares of forest by 2030 (i.e. the Bonn Challenge) would sequester up to $1.6 \mathrm{GtC}$ per year, equivalent to $14 \%$ of global carbon emissions [12], another estimates that conservation actions in all major natural terrestrial habitats could help provide around $30 \% \mathrm{CO} 2$ mitigation needed through to 2030 for $>66 \%$ chance of keeping warming to $<2{ }^{\circ} \mathrm{C}$ [13]. Decreasing sources and increasing sinks of GHGs through ecosystem stewardship and improvements in agriculture could each year reduce net emissions by billions of metric tons of $\mathrm{CO} 2$ equivalent at low cost (i.e. $<\$ 100$ per metric ton CO2) [13-15]. However, there are concerns over the practical and ethical implications of scaling up NbS for the purpose of GHG mitigation, including negative impacts on biodiversity and local land rights when policy favours the establishment of monocultures or low diversity plantations at the expense of natural ecosystems which may be richer in carbon and more resilient to climate change [10]. There are also concerns that enthusiasm for "natural climate solutions" may dilute efforts to decarbonize the economy [16].

Ultimately, societal benefits of $\mathrm{NbS}$ other than climate change mitigation may in some regions and at local scales be equally if not more valuable over the longterm [16]. For example, ecosystems can support human adaptation to the direct impacts and long-term hazards of climate change [5-8], especially if sustainably managed through local stewardship and in accordance with sound biodiversity science $[10,17]$.

\section{Nature-based Solutions for climate change adaptation}

A specific type of $\mathrm{NbS}$ targeting human adaptation to climate change is widely referred 
to as Ecosystem-based Adaptation (EbA). This is defined by the Convention on Biological Diversity (CBD) as: "the use of biodiversity and ecosystem services ... to help people adapt to the adverse effects of climate change" which "may include sustainable management, conservation and restoration of ecosystems, as part of an overall adaptation strategy that takes into account the multiple social, economic and cultural co-benefits for local communities."[18] EbA is often defined as being an alternative to "grey" engineering although in reality there is a spectrum of interventions, some including components of both, i.e. hybrid or "grey-green" approaches [3]. For some specific examples of $\mathrm{NbS}$ for climate change adaptation see Box 1.

\section{Box 1. Examples of Nature-based Solutions for climate change adaptation}

Protection from erosion and landslides

- China: A combination of afforestation, reforestation, and conservation of existing natural forests over 25 years in the Poyang Lake basin halved heavy soil erosion while increasing net carbon sequestration fivefold and net income for local farmers six-fold [47]. Meanwhile, restoration of natural herbaceous and shrubland vegetation on the Loess Plateau reduced soil erosion to a comparably or significantly greater extent than tree plantations, across a range of anti-soil erosion indices. Compared to afforested slopes, these naturally re-vegetated slopes also had 1.3-2 times higher soil water content [55].

Protection from inland flooding

- Canada: Reforestation in the headwaters of a river basin significantly reduced peak stream flows compared to an adjacent deforested basin, offering greater protection against flooding during spring snow melt [70].

- USA: Natural regeneration of mixed species hardwood watersheds following forest clearcutting reduced flood risk in lowland areas, reducing stream flows during periods of high precipitation by $>104 \mathrm{~L} / \mathrm{ha} /$ day [71].

- Europe: Restoration of all but one of six rivers reduced flood damage to crops and forests, and was associated with increased agricultural production, carbon sequestration and recreation, with a net societal economic benefit over unrestored rivers of $€ 1400 \pm 60072$.

Buffering natural resources against drier and more variable climates

- Panama: Agroforestry systems yield up to $21 \%$ higher economic return than farm mosaic approaches (i.e. where trees and crops are on separate parcels), including under a climate change scenario of more frequent droughts, in models that account for market and climate uncertainty [7]3.

- Europe: Agroforestry has reduced erosion, increased soil fertility, increased precipitation and reduced temperatures, with greatest effects in hotter, drier regions such as the Mediterranean basin (which is suffering from soil damage through increasing aridity under climate change) [74].

Reducing risks and impacts of wildfires

- Australia: Forest management by tree thinning in Eucalyptus delegatensis forest significantly altered forest structure and canopy openness, decreasing fuel loads and hazards, and thereby achieving a $30 \%$ reduction in the intensity and $20 \%$ reduction in spread of fires compared to un-thinned forests under simulations of severe weather conditions. Such actions could be critical to ensure the resilience of commercially valuable E. delegatensis to wildfires which are expected to increase in the future [75]. Protection from coastal hazards and sea level rise

- Global: Natural coastal habitats significantly reduce wave heights, with coral reefs and salt-marshes being most effective, causing a reduction of $70 \%$, followed by seagrass and kelp beds (36\%), and mangroves (31\%). Across 52 sites harnessing these habitats in coastal defence projects, nature-based solutions were 2-5 times more cost-effective at lower wave heights and at increased water depths compared to engineered structures [76].

- Gulf of Mexico: Construction of 'living shorelines' by aiding natural recruitment of oyster reefs can reduce vegetation retreat by $40 \%$ compared to unprotected sites, stabilizing the shoreline from the effects of waves and erosion, and increasing abundance and diversity of economically important species [32]. Moderating urban heatwaves and heat island effects

- Global: Green spaces are on average $0.94{ }^{\circ} \mathrm{C}$ cooler in the day than urban spaces, with stronger effects the larger the green space, according to a meta-analysis of 47 studies comparing the cooling effects of green spaces in cities (parks, areas with trees) with those of purely urban areas [77]. 
- Italy: Establishment of wetlands and green recreational space has been effective in reducing flood risks, with a $10 \%$ higher reduction of downstream flooding and $7.5 \%$ higher reduction of peak flow compared to potential grey infrastructure alternatives. $\mathrm{NbS}$ also outperform grey infrastructure in terms of water purification and provide greater socio-ecological benefits such as recreation and habitat for biodiversity [78].

While the evidence base is still developing [23], it is clear that $\mathrm{NbS}$ can, in certain contexts, provide low-risk low-cost solutions to many climate change-related impacts and offer key advantages over engineered solutions $[24,25]$. Engineered approaches "are designed and managed to be as simple, replicable and predictable as possible [26]" and have immediate, measurable effects on reducing specific impacts. However, they can be expensive and deliver few co-benefits, if any $[27,28]$. In contrast, $\mathrm{NbS}$ can be more affordable and, if properly implemented, may bring a wide range of ecosystem services especially for the more vulnerable sectors of society [29]. Crucially, ecosystems are more dynamic in that they "leave room for selfreorganization and mutability" and in this way may be more able to withstand and/or adapt to perturbation (i.e. are more resilient) compared to static engineered interventions [7, 29,30]. In contrast to most engineered approaches, $\mathrm{NbS}$ also have the potential to protect us against multiple impacts [27]. This is vital as these impacts seldom occur in isolation. This is particularly true of $\mathrm{NbS}$ in coastal ecosystems such as mangroves which can protect against flooding (e.g. by reducing water flow, wave height and wave energy during storm surges), as well as limit erosion (e.g. by promoting sedimentation and binding soil) $[31,32]$. Different ecosystems can also reinforce each other, and in doing so multiply benefits. For example, oyster reefs in the Gulf of Mexico act as natural breakwaters and thereby protect coastal vegetation. Efforts to aid the natural recruitment and formation of these reefs in the Gulf has reduced coastal vegetation retreat by $40 \%$ compared to unprotected sites, and this has stabilized the shoreline against wave damage and erosion. At the same time, reef restoration has increased the abundance and diversity of fish and invertebrate communities, including several economically important species [32] (Box 1).

There is also growing evidence of the economic benefits of maintaining natural habitats through avoided losses from climate change-related disasters. For example, the presence of coastal wetlands in northeast USA protected US\$625 million worth of property from direct flood damage during Hurricane Sandy [33]. Meanwhile, annual expected damages from flooding have been estimated to double and costs from frequent storms triple in the absence of reefs globally [34]. Studies directly comparing the cost-effectiveness of $\mathrm{NbS}$ versus engineered solutions are still rare, however. Nonetheless, one such evaluation in the Ba and Penang River catchments in Fiji found riparian buffers with native vegetation to be cheaper to establish than river dredging, and had a higher benefit-to-cost ratio in reducing flood damages, especially when accounting for climate change [35].

\section{Global recognition of the importance of Nature-based Solutions for adaptation}

Here we report on the prominence of $\mathrm{NbS}$ in the 141 Nationally Determined Contributions (NDCs) with adaptation components that were submitted to UNFCCC by all signatories of the Paris Agreement (Supplementary Information; Figure 1) [19]. We focus on the NDCs, rather than other policy documents (e.g. National Adaptation Plans), because the Paris Agreement has considerable political momentum, meaning that NDC targets are often in the limelight and under scrutiny. Furthermore, unlike any other policy process, the Agreement has an inbuilt ratchetmechanism for increasing ambition: every five years progress towards targets set out in the NDCs must be reported on, monitored and compared with other nations; what is included in the NDCs matters and has traction [20]. We focus on adaptation because this has been largely ignored in research on $\mathrm{NbS}$ in the NDCs, where to date the emphasis has been on the extent to which nations have incorporated forestry, agriculture and/or forest landscape restoration (FLR) for the purpose of increasing sinks and reducing sources of greenhouse gas 
emissions [21,22]. In our analyses, we make a distinction between interventions aimed at delivering direct positive adaptation outcomes and other social and/or economic benefits through ecosystem services (i.e. ecosystembased adaptation, EbA), and those aimed at delivering positive outcomes for species or habitats (i.e. which, for simplicity, we refer to as conservation).

Ecosystems in the Paris Agreement: As evidence grows for the efficacy of $\mathrm{NbS}$ to climate change, so the concept is gaining traction in international policy discourse 10 . In late 2018, NbS were endorsed in the IPCC 1.5 degrees Special Report36 and were declared a major theme or "pillar" in the UN's upcoming Climate Summit [37]. More recently, in the global assessment report on biodiversity and ecosystem services of the Intergovernmental Science-Policy Platform on Biodiversity and Ecosystem Services (IPBES)38, NbS were highlighted as a cost-effective way of meeting the Sustainable Development Goals. Of particular importance is the Paris Agreement of the United Nations Framework Convention on Climate Change (UNFCCC). This recognises the importance of ecosystems for mitigation and adaptation, calling on all Parties to acknowledge "the importance of the conservation and enhancement, as appropriate, of sinks and reservoirs of the greenhouse gases" and to "note the importance of ensuring the integrity of all ecosystems, including oceans, and the protection of biodiversity, recognized by some cultures as Mother Earth". It then includes in its Articles several references to ecosystems, forests and natural resources [39]. This notion has translated into high-level national intent, as revealed in our detailed comparative analysis of the NDCs (Supplementary Information; Figure 1) [19].

\section{Global recognition that ecosystems are} vulnerable to climate change: We found that two-thirds of NDCs (111/167)

acknowledge that ecosystems are vulnerable to climate change (Figure 1b)[19]. Some nations highlight negative impacts on ecosystems in general (China's NDC states that "climate change has significant impacts on global natural ecosystems"), while others focus on specific contexts (Morocco's NDC states that "climate change will have an impact on how vibrant and dynamic forest ecosystems are, on their ability to regenerate and to adapt to regular climate fluctuations, their biodiversity, their consistency, and their spatial distribution").

\section{Global recognition that Nature-based Solutions can reduce human vulnerability to climate change: The protection of ecosystems is a declared motivation for adaptation planning in $63 \%$ of} NDCs (105/167) and was the fifth most frequently mentioned intended outcome of adaptation planning (ranked below disaster risk reduction, increased resilience, food security and water security but above protection of the economy or human health; Figure 1c). Indeed, ecosystems feature in climate change adaptation "vision statements" in $76 \%$ (127) of the NDCs35. For some nations, the aim is to address impacts on ecosystems directly (e.g. the Republic of Congo's NDC emphasises the "protection of natural heritage, biodiversity, forests and fishery resources, through an adaptation approach rooted in the protection of ecosystems"). Others are instead explicit that protecting ecosystems is for the benefit of human communities (e.g. Cambodia commits to "promoting and improving the adaptive capacity of communities, especially through community based adaptation actions, and restoring the natural ecology system to respond to climate change" [35]).

Having articulated a broadly 'naturebased' vision for adaptation in their NDCs, most nations go on to propose a range of actions to achieve their vision. However, a small number had visions but no tangible actions35. Those with $\mathrm{NbS}$ actions describe the restoration and/or protection of ecosystems or the implementation of nature-based agricultural practices such as agroforestry (Figure 1d) [35]. Specifically, we found that the adaptation component of the NDCs of 70 nations ( $42 \%$ of NDCs) include actions that appear to have the characteristics of EbA as defined by the CBD18 (see above). For example, El Salvador states it will establish and manage one million hectares through an integrated approach "where forest areas will be rehabilitated and conserved, biological corridors will be established through the adoption of resilient agroforestry systems and transformation of agricultural areas with low carbon sustainable practices". An additional 33 
nations ( $20 \%$ of NDCs) outline conservation activities such as the establishment of protected areas or habitat restoration but without any explicit links to promoting social or ecological resilience to climate change or the involvement of local communities. For example, Bahrain refers to "a mangrove transplantation project for the cultivation of plants and planting mangrove seedlings in order to rehabilitate degraded coastal areas" and Tunisia commits to "conservation of the ecological functions of low-lying coastal areas". Twenty-seven countries, though lacking reference to $\mathrm{NbS}$ (EbA or conservation) in the adaptation component of their NDCs, refer to such actions or broad commitments in the mitigation component. For example, Vietnam seeks to "manage and develop sustainable forests, enhance carbon sequestration and environmental services". In total, 103 nations include $\mathrm{NbS}$ (i.e. $\mathrm{EbA}$ and/or conservation) in the adaptation component of their NDC (Figure 1a), 76 nations include them in both their adaptation and mitigation component, and an additional 27 include them as part of their mitigation plans only [35]. In other words, 130 nationsor $66 \%$ of all signatories to the Paris Agreement (78\% of NDCs1) - have articulated intentions of working with ecosystems, in one form or another, to address the causes and consequences of climate change. Such global recognition that ecosystems can help deliver the goals of the Paris Agreement is to be welcomed. However, in reality, national intentions to deliver $\mathrm{NbS}$ vary by level of economic development, region and habitat type, and rarely translate into measurable science-based targets.

\section{Developing nations embrace $\mathrm{NbS}$}

It is the poorest nations that presently experience the worst effects of climate change and who are in most urgent need of robust cost-effective adaptation action [36]. These nations also show the greatest movement towards embracing $\mathrm{NbS}$ as an adaptation tool in the NDCs (Figure 1a). NbS are referred to in the adaptation plans of all 30 nations classified as low-income by the World Bank (with $77 \%$ including EbA specifically) and all but four (92\%) of the 48 nations classified as least developed. In contrast, $\mathrm{NbS}$ actions are included in only nine (27\%) of 33 high-income nations (12\% include EbA) [19]. This discrepancy may reflect the higher dependency of the rural poor on natural resources and the lower economic cost of implementing $\mathrm{NbS}$ compared to high-tech engineered alternatives. It may also reflect the fact that United Nations institutions (notably UN Environment, but also the UN Development Programme and FAO) as well as international conservation organisations (e.g. IUCN, WWF, BirdLife International and Conservation International) have been implementing EbA projects in developing nations over the past ten years $[40,41]$. We note that no Annex 1 countries (i.e. industrialised OECD members and economies in transition) include $\mathrm{NbS}$ in their NDC adaptation plans, even though a number are implementing $\mathrm{NbS}$ on the ground. For example, many European countries are restoring rivers with the aim of mitigating flood risk [42]; the UK and Germany are both implementing managed coastal realignment to deal with flooding and erosion [43]; and in the USA, a wide range of $\mathrm{NbS}$ activities are being undertaken including to mitigate against coastal flooding, such as saltmarsh restoration and oyster reef rehabilitation $[32,33]$. These nations may not have included such information in their NDCs because the requirement to do so came after they had compiled them. Equally, they may not have viewed the NDC as a relevant vehicle to communicate adaptation intentions: the Kyoto Protocol emphasised stringent mitigation commitments by Annex 1 nations in particular, and in the decade leading up to the Paris Agreement adaptation was largely ignored. Consequently, recognition of $\mathrm{NbS}$ as an adaptation tool is more global than indicated across the current iteration of NDCs. As these are revised in time for 2020, and indeed as climate impacts on Annex 1 nations intensify, so we may see greater balance between mitigation and adaptation planning by all nations, with $\mathrm{NbS}$ recognised as an important tool for achieving synergy between them.

\section{Harnessing Nature-based Solutions in all ecosystems}

\footnotetext{
${ }^{1}$ Not all signatories submitted an NDC (see Supplementary Information)
} 
The ecosystems most commonly referred to in the adaptation component of the NDCs are terrestrial forests or woodlands, i.e. their protection, restoration (reforestation) or afforestation; these are highlighted in the adaptation component of $68 \mathrm{NDCs}$, i.e. $41 \%$ (Figure 1d). The protection and/or restoration of coastal or marine habitats appeared in 47 NDCs $(28 \%$ of the total, but $37 \%$ of NDCs from nations with coasts), followed by similar actions in river catchments, including wetlands ( $28 \%$ of NDCs). Much less common are references to working with grasslands and rangelands $(10 \%$ of NDCs) or montane habitats as an adaptation approach $(4 \%$ of NDCs; Figure 1d). Almost all examples of grassland or rangeland $\mathrm{NbS}$ adaptation actions come from Africa, despite the extensive presence of these habitats on other continents. Nature-based agricultural practices, such as agroforestry, were included in the adaptation component of 39 NDCs (i.e. 23\%). These were strongly emphasised in African nations [19], possibly reflecting their low cost and multiple benefits compared to industrial agriculture [44], especially to smallholder farmers who have a long history of working with nature [45].

The emphasis in the NDCs on forests and forestry may simply reflect the fact that forests are high on the agenda in international negotiations and in national policymaking contexts (e.g. Reduced Emissions from Deforestation and Degradation (REDD), New York Declaration on Forests, and the Bonn Challenge) [10]. The policy focus on forests to date has largely been framed in terms of their value for mitigation (i.e. as carbon sinks). Nevertheless, it may have created awareness among policymakers of, for example, sustainable forest management, arguably paving the way for the inclusion of such actions in adaptation plans. Forests may also be regarded by national policymakers as a valuable economic resource (i.e. for timber, non-timber forest products) whereas the direct economic value of other habitats is perhaps less clear. An emphasis on forests in the NDCs may also reflect a more extensive evidence base for the effectiveness of these habitats in providing key regulating services, in particular erosion control along coasts [45] and in river catchments $[47,48]$. Conversely, fewer studies have rigorously quantified the extent to which grasslands or montane habitats protect communities from climate change impacts [49].

The focus on forests and forestry is problematic if it comes at the expense of working with other ecosystems, such as natural grasslands and peatlands that may be more resilient to climate change impacts and/or support human adaptation in other ways [50]. Evidence of forest dieback across the globe as a result of climate stress (in particular, drought and increased frequency of wildfires) [51] suggests that reforestation might not be a viable long-term adaptation solution in some regions. Meanwhile, scientific research increasingly suggests that areas allowed to regenerate naturally deliver a wider range of vital climate change adaptation services with fewer trade-offs [50]. For example, although large scale afforestation projects have dramatically reduced soil erosion in China (e.g. on the Loess Plateau) [52], they have also increased water shortages [53] and reduced biodiversity [54]. Conversely, areas allowed to regenerate naturally (e.g. into herbaceous cover and shrub land) provide comparable levels of erosion control without compromising water supply or biodiversity [55].

Climate change policy, whether articulated in the NDCs or other national plans, must not prioritise forests at the cost of other vitally important ecosystems, and must consider the balance in the delivery of different ecosystems' services. Those advocating for increased ambition for nature in climate change policy need to bear this in mind and be more inclusive in how they describe the value of $\mathrm{NbS}$. Whether arguing for nature's role in climate change mitigation and/or adaptation, the potential value of all ecosystems must be taken into account [10] .

\section{Developing policy targets for Nature-based Solutions that promote socioecological resilience}

While many nations articulate a theoretical commitment to $\mathrm{NbS}$ as an adaptation tool, this rarely translates into clear targets in the NDCs. Of the 103 NDCs that include NbS adaptation actions, only 30 provide measurable (i.e. timebound, quantitative) targets; the remainder provide broad goals which are difficult to measure [19]. For example, Morocco aims to 
protect "natural heritage, biodiversity, forestry and fishery resources, through an ecosystembased adaptation approach" and South Sudan will strive to "develop forest reserves and management plans to protect watersheds and improve future water availability". Although such aims are important, without more context-specific, measurable targets and suitable indicators it will be difficult to determine the extent to which they are being achieved.

Even where measurable $\mathrm{NbS}$ adaptation targets exist in the NDCs, they tend to focus on the extent of lands to be afforested, reforested or restored, rather than the quality of those lands. Afforestation accounts for $22 \%$ of the 64 adaptation targets included in 30 NDCs, and the protection and/or restoration of specific areas of habitat (usually forest) within given timeframes accounts for $48 \%$ of targets [19]. For example, Bolivia states that it will "increase forest areas with integrated and sustainable community management approaches with 16.9 million hectares in 2030 , in reference to 3.1 million hectares by 2010 ", Burundi states it will increase "forest cover by $20 \%$ by 2025 ", and Mongolia includes an intention to increase forest area "to $9 \%$ by 2030 through reforestation activities"[19].

This focus on reforestation and/or afforestation is problematic, as it can encourage the establishment of plantations of fast growing exotic species [50,56]. For example, $45 \%$ of the 350 Mha currently pledged for reforestation to meet the Bonn Challenge is set to become commercial plantations [56]. While fast-growing singlespecies plantations may sequester carbon and reduce vulnerability to a specific climate change impacts in the short-term, their capacity to support human adaptation or store carbon over the long-term may be impaired by changing conditions and disturbances that are becoming more severe under climate change [57]. For ecosystems to provide services to people, they must themselves be able to resist, recover and/or adapt to these changes. Such resilience is, in turn, strongly determined by habitat connectivity, heterogeneity and diversity [58]. Connectivity allows for migration and range shifts to track moving ecological niches as an adaptive response to climate change [59]. Diversity, meanwhile, allows for sustained productivity through extreme floods and droughts [60], pests and diseases [61] via the buffering effects of multiple species which differ independently in their responses to similar environmental conditions [62]. Genetic diversity also safeguards the evolutionary potential for adaptation to a changing environment [63].

Therefore, to provide regulating and other adaptation services over the long-term, therefore, $\mathrm{NbS}$ targets must enhance ecological attributes that underpin functional resilience. However, only thirty-one nations include intentions in their NDCs to improve ecosystem resilience (e.g. Kenya's adaptation vision is to "enhance the resilience of ecosystems to climate variability and change"). None go on to outline how this might be achieved in practice, and only two NDCs explicitly link ecosystem resilience with biodiversity. Jordan states that "adaptation strategies and measures in biodiversity should be prepared and implemented in order to achieve sustainable, healthy and resilient ecosystems in the future under threats of climate change and other stressors", and Rwanda "intends to use mixedspecies approaches which contribute greatly to the achievement of both mitigation objectives and adaptation benefits of ecosystem resilience and biodiversity."

Ideally NbS adaptation targets should support biodiversity (species and/or functional diversity) by emphasising the protection and restoration of native vegetation such as old growth forests, mangroves and natural wetlands, and by enhancing connectivity between and heterogeneity within these ecosystems. They should also encourage working with nature in such a way as to secure a range of ecosystem services that i) reduce exposure (e.g. limit coastal flooding), ii) build adaptive capacity (e.g. empower local communities to manage their natural environment), and iii) reduce sensitivity to the impacts of climate change (e.g. secure diverse portfolios of livelihoods to increase resilience to climatic shocks) [64]. In other words, targets must derive from understanding of the effectiveness of $\mathrm{NbS}$, not only on dealing with direct climate change impacts but also on their capacity to provide positive outcomes for ecosystems and people [65]. The dynamic and complex nature of socioecological systems [66] means we are unlikely to find meaningful adaptation targets and simple metrics that work at scales. Instead the emphasis must be on devising suites of locally relevant, context- 
specific metrics that draw on understanding of the effects of different management practices on socioecological ecosystems and their resilience under different climate change scenarios.

\section{Integrating science, local knowledge and policy on Nature- based Solutions}

For the adaptation needs of communities and ecosystems to be met by NbS, policy targets must be informed by the best available science and local knowledge. To enable more nations to develop robust $\mathrm{NbS}$ targets and indicators, scientists must work together with policy makers to identify their knowledge needs, and then to consolidate and translate the science (in particular that relating to ecosystem resilience) so that it is in a form most relevant and understandable to them. In tandem, researcher and practitioner communities must work together to consolidate and translate scientific, traditional and experiential knowledge about the scales and contexts in which NbS are effective [67]. Policymakers need stronger evidence, in a form that is readily useable at the policy level to make informed responses to climate change while supporting biodiversity, and tools are being developed to support this process $[19,68]$. This can be a virtuous cycle if policymakers simultaneously commit to engaging with scientists as well as to scaling up funding for research into what makes $\mathrm{NbS}$ effective for people and ecosystems (see below). Many NDCs already recognise that action plans addressing climate threats should be sciencebased and make high-level commitments to this. For example, 100 of the 167 NDCs include current or planned research or monitoring measures, such as the development of climate information (e.g. improving or expanding weather station networks and data, using climate models and developing climate change scenarios) and research into more effective processes or measures (e.g. climate risk and vulnerability assessment processes and adaptation technologies). Such actions will be critical in strengthening the scientific basis for future adaptation planning, including the design, implementation and evaluation of $\mathrm{NbS}$ actions.
In addition to consolidating existing evidence, the research community must also address major knowledge gaps in the science underlying $\mathrm{NbS}$ (reviewed in [65]). Studies are needed into how the performance of $\mathrm{NbS}$ relative to alternatives varies across different temporal and spatial scales, levels of urgency, socio-economic contexts, and ecological settings, and the extent to which they are "climate proofed" $[2,64]$. There is also uncertainty about how different climate change adaptation services trade off against one another and over what scales, and around how climate impacts interact with other stressors (e.g. land-use change) to influence the flow of services and determine tipping points beyond which ecosystem functions fail and cannot recover. At the same time, there is an urgent need to develop more robust mechanisms for evaluating and contrasting the performance of different approaches, and for defining, measuring and tracking the effectiveness of NbS taking future climate change into account [69]. New research is also needed to identify novel forms of financing and incentivising the implementation of $\mathrm{NbS}$, and of the economic and governance implications of these instruments.

To address such knowledge gaps demands a transdisciplinary approach, one that integrates knowledge from across the natural, physical and social sciences, from finance, governance and political ecology as well as from local and traditional knowledge. This is vital. Even if future research reduces uncertainty about the contexts and scales at which nature can support human adaptation, without appropriate governance structures in place and suitable flows of finance, $\mathrm{NbS}$ will not be implemented on the ground [65].

\section{Embedding Nature-based Solutions in the post-2030 development agenda}

Ecosystems are central to the adaptation ambition of many countries across the globe. However, of those countries implementing or planning to implement $\mathrm{NbS}$ actions, very few include clear and measurable targets towards which progress can be assessed. Given growing evidence that $\mathrm{NbS}$ can provide lowcost, low-risk adaptation options that provide a 
wide range of vital ecosystem services and offer protection against multiple impacts, efforts to engage all countries in $\mathrm{NbS}$ should be stepped up to inform target -setting in the next iteration of NDCs. We found that for many nations there is a mismatch between high-level visions and on-the-ground actions stated in NDCs. In a handful of such cases, detailed plans are instead provided in other national policy documents (e.g. National Adaptation Plans), suggesting the need for greater coherence among different national policy processes. For the majority, however, the mismatch indicates a lack of understanding of how best to integrate $\mathrm{NbS}$ within adaptation planning processes, and underscores the need for better support to policymakers and planners in translating theoretical $\mathrm{NbS}$ approaches into locally relevant actions.

Support for policymakers and practitioners should include much greater engagement, including two-way knowledge exchange, with the ecosystem science community, making use of the opportunities and incentives provided by international initiatives such as the Nairobi Work Programme of the UNFCCC. To address the mismatch between ambition and action, the science, practitioner and policy communities must work together to clarify and properly disseminate information on what makes $\mathrm{NbS}$ effective; build practitioners' capacity to develop robust adaptation plans, re-tuned to local socio-ecological contexts; access suitable levels of adaptation finance and/or technical support; and ultimately implement effective $\mathrm{NbS}$, where appropriate, for the benefit of human societies and the ecosystems on which they depend.

With incentives such as the Bonn Challenge, New York Declaration on Forests, Aichi Biodiversity Targets and the CBD post2020 Biodiversity Framework, growing numbers of countries are pledging to work with, protect and restore their ecosystems. Provided these pledges are met by actions that are informed by biodiversity science and implemented through local stewardship, they will help nations deliver on international commitments with limited finance, and ultimately achieve sustainable and equitable development in a warming world.

\section{Acknowledgements.}

This study was supported by a Natural Environmental Research Council Knowledge Exchange Fellowship to N Seddon, with additional funding from the University of Oxford (John Fell Fund, Department of Zoology and Wadham College). The study also formed part of the International Climate Initiative (IKI) project 'Ecosystem-Based Adaptation: Strengthening the Evidence and Informing Policy', coordinated by the International Institute for Environment and Development, the International Union for the Conservation of Nature and the World Conservation Monitoring Centre of the United Nations Environment Programme. The German Federal Ministry for the Environment, Nature Conservation and Nuclear Safety (BMU) supports the IKI on the basis of a decision adopted by the German Bundestag.

\section{Author contributions.}

N Seddon, E Daniels, R Davis and R Harris collated the NDC data and conducted the analyses. N Seddon and E Daniels wrote the manuscript, with significant input from $\mathrm{R}$ Davis; all co-authors commented.

\section{Financial support.}

See acknowledgements.

\section{Conflicts of interest}

None.

\section{Ethical standards.}

This research and article complies with Global Sustainability's publishing ethics guidelines.

\section{References}

1. World Economic Forum. Global Risks Report 2019 14th Edition (2019).

2. Jones, H. P. et al. Harnessing nature to help people adapt to climate change. Nat. Clim. Chang. 2, 504-509 (2012).

3. Browder, G. et al. Integrating Green and Gray: Creating Next Generation Infrastructure. Washington, DC: World Bank and World Resources Institute. https://openknowledge.worldbank.org/ handle/10986/31430 License: CC BY 4.0. (2019)

4. Stein, B. A. et al. Preparing for and managing change: climate adaptation 
for biodiversity and ecosystems.

Front. Ecol. Environ. 11, 502-510 (2013).

5. Nesshöver, C. et al. The science, policy and practice of nature-based solutions: An interdisciplinary perspective. Sci. Total Environ. 579, 1215-1227 (2017).

6. Keeler, B. L. et al. Social-ecological and technological factors moderate the value of urban nature. Nature Sustainability 2, 29-38 (2018).

7. Eggermont, H. et al. Nature-based Solutions: New Influence for Environmental Management and Research in Europe. GAIA 24/4: 243248 (2015).

8. Cohen-Shacham, E. et al. (eds.) Nature-based Solutions to address global societal challenges. Gland, Switzerland: IUCN. xiii $+97 \mathrm{pp}$ (2016).

9. European Commission. Towards an EU research and innovation policy agenda for nature-based solutions \& re-naturing cities. Final report of the Horizon 2020 expert group on 'Naturebased solutions and re-naturing cities' (2015).

10. Seddon, N. et al. Grounding naturebased climate solutions in sound biodiversity science. Nature Climate Change 9, 84-87 (2019).

11. Cardinale, B. J. et al. Biodiversity loss and its impacts on humanity. Nature 486, 59-67 (2012).

12. Dave, R. et al. Bonn Challenge Barometer of Progress: Spotlight Report, Gland, Switzerland: IUCN (2017).

13. Griscom, B. W. et al. Natural climate solutions. Proc. Nationl. Acad. Sci.114, 11645-11650 (2017).

14. Smith, P. et al. How much land-based greenhouse gas mitigation can be achieved without compromising food security and environmental goals? Glob. Change Biol. 19, 2285 (2013).

15. United Nations Environment Programme (UNEP), "The emissions gap report 2017: A UN Environment synthesis report" (UNEP, Nairobi, Kenya, 2017); https://wedocs. unep.org/bitstream/handle/20.500.118 22/22070/ EGR_2017.pdf. (2017).
16. Andersen et al. Natural climate solutions are not enough. Science 363, 933-934 (2019).

17. Kremen, C. \& Merenlender, A. M. Landscapes that work for biodiversity and people. Science 362, 304 (2018).

18. Secretariat of the Convention on Biological Diversity. Connecting Biodiversity and Climate Change Mitigation and Adaptation: Report of the Second Ad Hoc Technical Expert Group on Biodiversity and Climate Change (2009).

19. Nature-based Solutions Policy Platform: www.nbspolicyplatform.org.

20. NDC Partnership http://ndcpartnership.org/

21. Forsell, N. et al. Assessing the INDCs' land use, land use change, and forest emission projections. Carbon Balance and Management 1, 26 (2016).

22. Grassi, G. et al. The key role of forests in meeting climate targets requires science for credible mitigation. Nature Climate Change 7, 220 (2017).

23. Nalau, J. et al. Ecosystem-based Adaptation: A review of the constraints. Environmental science and Policy 89, 357-364 (2018).

24. The Royal Society (2014) Resilience to extreme weather.

25. Keesstra, S. et al. The superior effect of nature based solutions in land management for enhancing ecosystem services. Science of the Total Environment 610, 997-1009 (2018).

26. Hoffert, M. I. et al. Advanced technology paths to global climate stability: Energy for a greenhouse planet. Science 298, 981-987 (2002).

27. Munang, R. et al. Climate change and Ecosystem-based Adaptation: a new pragmatic approach to buffering climate change impacts. Current Opinion in Environmental Sustainability 5, 67-71 (2013).

28. Chong, J. Ecosystem-based approaches to climate change adaptation: progress and challenges. International Environmental Agreements: Politics, Law and Economics 14, 391-405 (2014). 
29. Garmestani, A. S. \& Benson, M. H. A framework for resilience-based governance of socio-ecological systems. Ecology and Society 18, Article 9. (2013)

30. Krauss, K. W. et al. Created mangrove wetlands store belowground carbon and surface elevation change enables them to adjust to sea-level rise. Scientific Reports 7, 1030 (2017)

31. Spalding, M. D. et al. Coastal ecosystems: A critical element of risk reduction. Cons. Letts. 7, 293-301 (2014).

32. Scyphers, S. B. et al. Oyster reefs as natural breakwaters mitigate shoreline loss and facilitate fisheries. PLoS ONE 6, e22396 (2011).

33. Narayan, S. et al. The Value of Coastal Wetlands for Flood Damage Reduction in the Northeastern USA. Sci. Rep. 7, 9463 (2017).

34. Beck, M. et al. Nature Communications 9, 2186 (2018).

35. Daigneault, A. et al. Dredging versus hedging: Comparing hard infrastructure to ecosystem-based adaptation to flooding. Ecol. Econ. 122, 25-35 (2016).

36. IPCC. Global warming of $1.5^{\circ} \mathrm{C}$. An IPCC Special Report on the impacts of global warming of $1.5^{\circ} \mathrm{C}$ above preindustrial levels and related global greenhouse gas emission pathways, in the context of strengthening the global response to the threat of climate change, sustainable development, and efforts to eradicate poverty [V. Masson-Delmotte, P. Zhai, H. O. Pörtner, D. Roberts, J. Skea, P.R. Shukla, A. Pirani, W. MoufoumaOkia, C. Péan, R. Pidcock, S. Connors, J. B. R. Matthews, Y. Chen, X. Zhou, M. I. Gomis, E. Lonnoy, T. Maycock, M. Tignor, T. Waterfield (eds.)] World Meteorological Organization, Geneva, Switzerland (2018).

37. United Nations Climate Summit 2019: http://www.un.org/en/climatechange/u n-climate-summit-2019.shtmlN climate summit

38. IPBES. Global assessment report on biodiversity and ecosystem services of the Intergovernmental Science- Policy
Platform on Biodiversity and Ecosystem Services. E. S. Brondizio, J. Settele, S. Díaz, and H. T. Ngo (editors). IPBES Secretariat, Bonn, Germany (2019).

39. For example, Article 5.2 encourages Parties to adopt "...policy approaches and positive incentives for activities relating to reducing emissions from deforestation and forest degradation, and the role of conservation and sustainable management of forests and enhancement of forest carbon stocks in developing countries; and alternative policy approaches, such as joint mitigation and adaptation approaches for the integral and sustainable management of forests, while reaffirming the importance of incentivizing, as appropriate, noncarbon benefits associated with such approaches".

40. Rizvi, A. R. Nature Based Solutions for Human Resilience A Mapping Analysis of IUCN's Ecosystem Based Adaptation Projects (2014).

41. Osti, M. et al. UNEP's portfolio of Ecosystem-based Adaptation (EBA) projects around the world. Internal Summary unpublished report (2015).

42. Giełczewski, M. Assessing the societal benefits of river restoration using the ecosystem services approach. Hydrobiologia 769, 121135 (2016).

43. Rupp-Armstrong, S. \& Nicholls, R. J. Coastal and estuarine retreat: a comparison of the application of managed realignment in England and Germany. J. Coast. Res. 236, 14181430 (2007).

44. Scherr, S. J. \& Sthapit, S. Sustainable Land Management in Africa: Opportunities for Climate Change Adaptation (TerrAfrica, 2009).

45. Mbow et al. Agroforestry solutions to address food security and climate change challenges in Africa. Sustainability 6, 61-67 (2014).

46. Temmerman, S. et al. Ecosystembased coastal defence in the face of global change. Nature 504, 79-83 (2013).

47. Huang, L. et al. Forest restoration to achieve both ecological and economic 
progress, Poyang Lake basin, China. Ecol. Eng. 44, 53-60 (2012).

48. Dadson et al. A restatement of the natural science evidence concerning catchment-based 'natural' flood management in the UK. Proceedings of the Royal Society A, 473: 20160706 (2017).

49. Doswald, N. et al. Effectiveness of ecosystem-based approaches for adaptation: review of the evidencebase. Clim. Dev. 6, 185-201 (2014).

50. Brancalion, P.H.S. \& Chazdon, R. Beyond hectares: four principles to guide reforestation in the context of tropical forest and landscape restoration Restoration Ecology doi: 10.1111/rec.12519 (2017)

51. Allen, C. D. et al. A global overview of drought and heat-induced tree mortality reveals emerging climate change risks for forests. Forest Ecology and Management 259, 660684 (2010).

52. $\mathrm{Xu}, \mathrm{J}$. C. China's new forests aren't as green as they seem. Nature 477, 371 (2011).

53. Jia, X. et al. Soil moisture decline due to afforestation across the Loess Plateau, China. Journal of Hydrology 546, 113-122 (2017).

54. Hua, F. Y. et al. Opportunities for biodiversity gains under the world's largest reforestation programme. Nature Communications 7,12717 (2016).

55. Jiao, J. et al. Assessing the ecological success of restoration by afforestation on the Chinese Loess Plateau.

Restoration Ecology, 20, 240-249 (2012).

56. Lewis et al. Restoring natural forests is the best way to remove atmospheric carbon Nature 568, 25-28. (2019).

57. Frank et al. Effects of climate extremes on the terrestrial carbon cycle: concepts, processes and potential future impact. Global Change Biol. 21, 2861-2880 (2015).

58. Oliver, T. H. et al. Biodiversity and resilience of ecosystem functions. Trends Ecol Evol 30, 673-684 (2015).

59. McGuire, J. L. et al. Achieving climate connectivity in a fragmented landscape PNAS (2016).
60. Hutchinson, C. et al. Scientific Reports 8,15443 (2018).

61. Jactel, H. t al. Curr. For. Rep. 3, $223-$ 243 (2017).

62. Loreau, M. \& de Mazancourt, C. Species synchrony and its drivers: Neutral and nonneutral community dynamics in fluctuating environments. The American Naturalist 172, 48-66 (2008).

63. Mijangos, J. L. et al. Contribution of genetics to ecological restoration. Molecular Ecology 24:22-37 (2015)

64. Lavorel, S. et al. Mustering the power of ecosystems for adaptation to climate change. Environmental Science and Policy 92, 87-97 (2019).

65. Seddon, N. et al. Understanding the value and limits to nature-based solutions to climate change. Phil. Trans B. (In press).

66. Ostrom, E. A general framework for analyzing sustainability of socialecological systems. Science 325, 419422 ( 2009)

67. Kabisch et al. Nature-based solutions to climate change mitigation and adaptation in urban areas: perspectives on indicators, knowledge gaps, barriers, and opportunities for action. Ecology and Society 21 (2016)

68. https://www.iied.org/help-pilotnavigator-tools-for-ecosystem-basedadaptation

69. Calliari, E. et al. An assessment framework for climate-proof naturebased solutions. Science of the Total Environment 656, 91-700 (2019).

70. Buttle, J. M. Streamflow response to headwater reforestation in the Ganaraska River basin, southern Ontario, Canada. Hydrological Processes 25, 3030-3041 (2011).

71. Kelly, C. N. et al. Streamflow response to increasing precipitation extremes altered by forest management. Geophysical Research Letters 43, 3727-3736 (2016).

72. Vermaat, J. E. et al. Assessing the societal benefits of river restoration using the ecosystem services approach. Hydrobiologia 769, 121135 (2016).

73. Paul, C. et al. Agroforestry versus farm mosaic systems-Comparing 
land-use efficiency, economic returns and risks under climate change effects. Science of the Total Environment 587, 22-35 (2017).

74. Torralba, M. et al. Do European agroforestry systems enhance biodiversity and ecosystem services? A meta-analysis. Agriculture, Ecosystems and Environment 230, 150-161 (2016).

75. Volkova, L. et al Impact of mechanical thinning on forest carbon, fuel hazard and simulated fire behaviour in Eucalyptus delegatensis forest of south-eastern Australia. Forest Ecology and Management 405, 92-100 (2017).
76. Narayan, S. et al. The effectiveness, costs and coastal protection benefits of natural and nature- based defences. PLOS One 11, e0154735 (2016).

77. Bowler, D. E. et al. Urban greening to cool towns and cities: A systematic review of the empirical evidence. Landscape and Urban Planning 97, 147-155 (2010).

78. Liquete, C. et al. Integrated valuation of a nature-based solution for water pollution control. Highlighting hidden benefits. Ecosystem Services 22, 392401 (2016). 


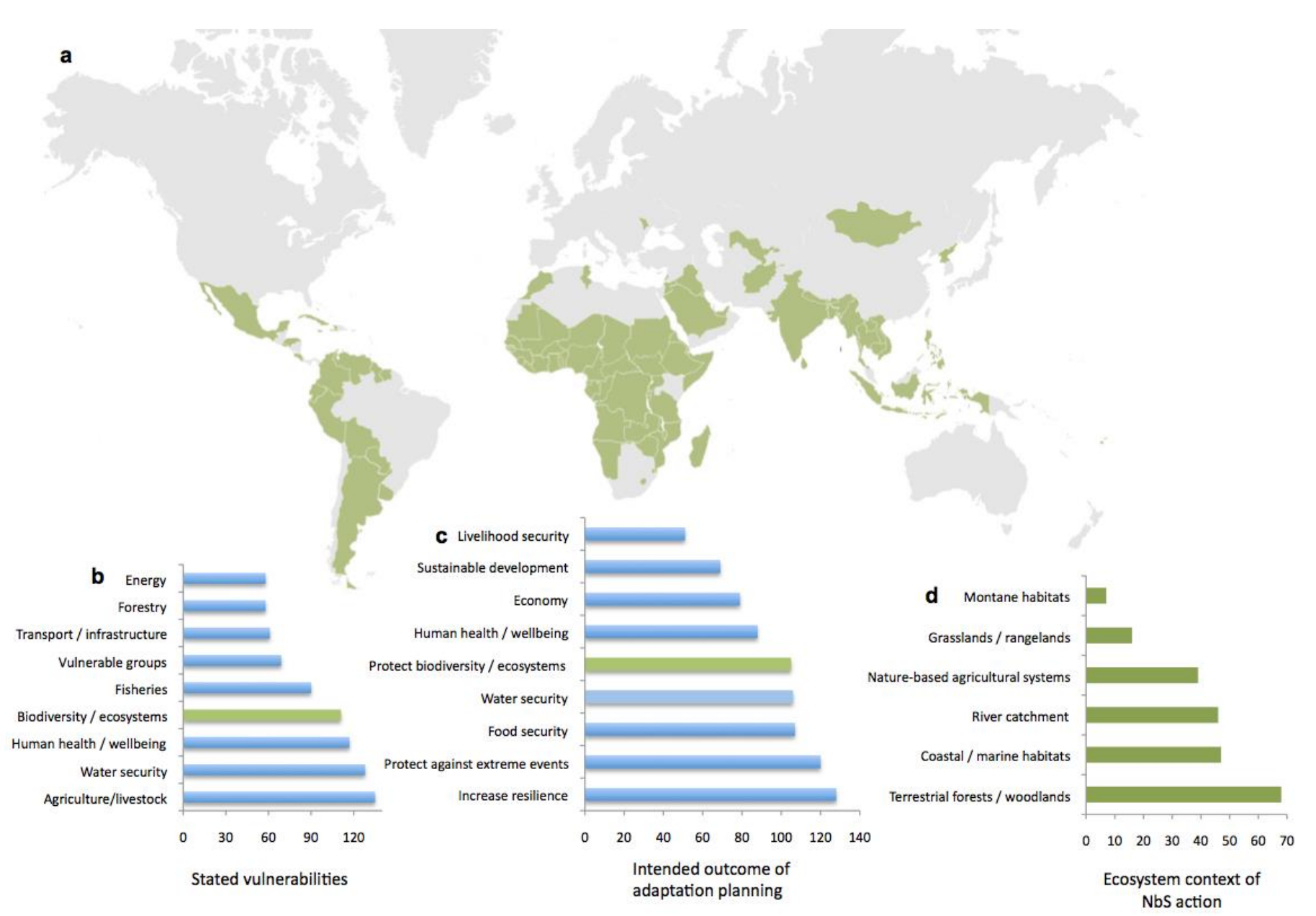

Fig. 1

Overview of how ecosystems and nature-based solutions are included in the adaptation components of all

Nationally Determined Contributions submitted to UNFCCC by signatories of the Paris Agreement. a, Global

distribution of those nations that included NbS (i.e. EbA and conservation) actions in the adaptation components of the NDCs

$(n=103)$. b. Sectors most commonly described as being vulnerable to climate change; biodiversity and/or ecosystems are ranked fourth (green bar). c, Most common reasons given for developing an adaptation plan; protecting biodiversity and/or ecosystems are ranked fifth (green bar). d, Habitat types or ecological contexts in which NbS actions for adaptation are described; NbS actions most commonly involve terrestrial forests and woodlands. 